\title{
Author Correction: Tomorrow's biggest microbial threats
}

Mike May

Correction to: Nature Medicine https://doi.org/10.1038/s41591-021-01264-2, published online 15 March 2021.

In the version of this article initially published, "more than one third" in the second sentence of the second paragraph in the first subsection ('Fear of the known') was incorrect. The correct proportion is 'about 2.5\%'. The error has been corrected in the HTML and PDF versions of the article.

Published online: 15 April 2021

https://doi.org/10.1038/s41591-021-01341-6

๑) Springer Nature America, Inc. 2021

\section{Author Correction: Placebo use and unblinding in COVID-19 vaccine trials: recommendations of a WHO Expert Working Group}

Jerome Amir Singh (D), Sonali Kochhar, Jonathan Wolff and The WHO ACT-Accelerator Ethics \& Governance

Working Group*

Correction to: Nature Medicine https://doi.org/10.1038/s41591-021-01299-5, published online 16 March 2021.

In the version of this article initially published, the affiliation for author Ehsan Shamsi-Gooshki (University of Tehran, Tehran, Iran) was incorrect. The correct affiliation is: Tehran University of Medical Sciences, Tehran, Iran. The error has been corrected in the HTML and PDF versions of the article.

${ }^{*} \mathrm{~A}$ list of authors and their affiliations appears online.

Published online: 4 May 2021

https://doi.org/10.1038/s41591-021-01360-3

(c) The Author(s), under exclusive licence to Springer Nature America, Inc. 2021 